\title{
El cuidado de enfermería y su evolución histórica: una revisión integrativa
}

\section{Nursing care and historical evolution: an integrative review \\ O cuidado de enfermagem e sua evolução histórica: uma revisão integrativa}

Camila Neumaier Alves ${ }^{1}$, Ana Cândida Lopes Corrêa ${ }^{2}$, Marilu Correa Soares ${ }^{3}$, Sonia Maria Könzgen Meincke

${ }^{1}$ Enfermeira, Mestre, Doutoranda, Programa de Pós-Graduação em Enfermagem, Universidade Federal de Pelotas. E-mail: camilaenfer@gmail.com

${ }^{2}$ Enfermeira, Mestre, Doutoranda, Programa de Pós-Graduação em Enfermagem, Universidade Federal de Pelotas. E-mail: analopescorrea@hotmail.com

${ }^{3}$ Enfermeira Obstetra, Doutora, Professora do Curso de Enfermagem da Universidade Federal de Pelotas. E-mail:enfmari@uol.com.br

${ }^{4}$ Enfermeira, Doutora, Professora do Curso de Enfermagem da Universidade Federal de Pelotas. E-mail: meinckesmk@gmail.com

Cómo citar este artículo en edición digital: Neumaier Alves, C., Lopes Corrêa, A.C., Correa Soares, M. y Könzgen Meincke, S.M. ${ }^{a}$. (2015). O cuidado de enfermagem e sua evolução histórica: uma revisão integrativa. Cultura de los Cuidados (Edición digital), 19(43). Disponible en: <http://dx.doi.org/10.14198/cuid.2015.43.09>

Correspondencia: Camila Neumaier Alves. Rua Gomes Carneiro, no 01, Sala 201. Pelotas (Rio Grande do Sul/Brasil). Correo electrónico: camilaenfer@gmail.com

Recibido: 14/07/2015; Aceptado:14/10/2015

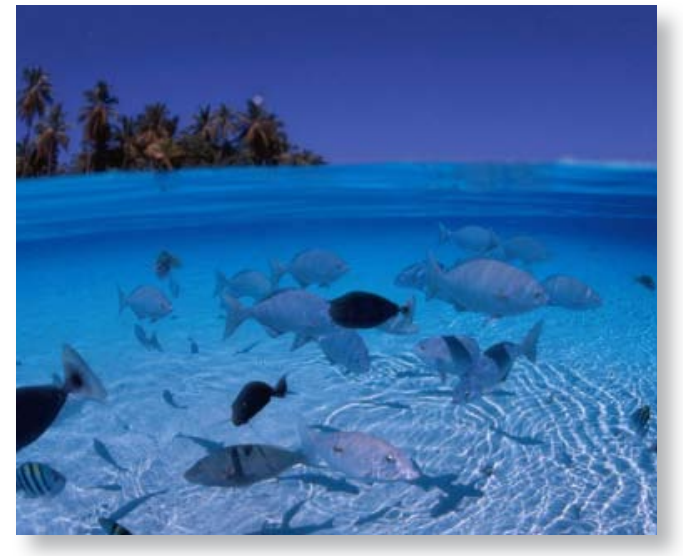

ABSTRACT

The aim is to identify the publications available in the literature about the history of nursing in the field of care provided by nurses. The method used included the integrative literature review, which is one of evidence-based practice resources. The search was conducted in August 2014, in the Virtual Library of Health. Were included articles that presented in titles or ab- stracts references to the history of nursing or the nursing care. Were excluded articles unrelated to the subject studied. For identification of the results it was decided to make a descriptive analysis of the publications and grouping of topics. It was found that the productions focus their writings on the contributions of Florence, religion and other for nursing. Moreover, prevailed discussions about the evolution of nursing through the ages and the history of care. It is understood that these findings are fundamental to locate the nurse in its history, since the nursing remains in progress and we are all actors in this art.

Keywords: Nursing; History of Nursing; Nursing Care.

\section{RESUMEN}

El objetivo es identificar las publicaciones disponibles en la literatura sobre la historia de la enfermería en el ámbito de la atención pres- 
tada por los enfermeros. El método utilizado incluyó la revisión integradora de la literatura, que es uno de los recursos de la práctica basada en la evidencia. La búsqueda se realizó en agosto de 2014, en la Biblioteca Virtual de Salud. Fueran incluídos artículos que presentan en títulos o resúmenes referencias a la historia de la enfermería o la atención de enfermería. Se excluyeron los artículos no relacionados con el tema estudiado. Para la identificación de los resultados se decidió realizar un análisis descriptivo de las publicaciones y agrupación de los temas. Se encontró que las producciones centran sus escritos sobre las contribuciones de Florence, la religión y otros para la enfermería. Por otra parte, se impuso discusiones acerca de la evolución de la enfermería a través de los siglos y la historia de la atención. Se entiende que estos resultados son fundamentales para localizar el enfermero en su historia, ya que la enfermería sigue en curso y somos todos actores de esta arte.

Palabras clave: Enfermería; Historia de la enfermeira; Cuidados de Enfermería.

\section{RESUMO}

Objetiva-se identificar as publicações disponíveis na literatura acerca da história da enfermagem, no campo dos cuidados realizados por enfermeiros. O método utilizado compreendeu a revisão integrativa da literatura, que é um dos recursos da prática baseada em evidências. A busca foi realizada em agosto de 2014, na Biblioteca Virtual da Saúde. Incluíram-se artigos que apresentaram nos títulos ou resumos referências à história da enfermagem ou aos cuidados de enfermagem. Excluíram-se artigos não relacionados à temática estudada. Para identificação dos resultados optou-se por fazer uma análise descritiva das publicações e agrupamento dos temas. Identificou-se que as produções centram suas escritas nas contribuições de Florence, da religião e de outros povos para a enfermagem. Ademais, prevaleceram discussões acerca da evolução da enfermagem através dos tempos e a história dos cuidados. Compreende-se que estes achados são fundamentais para situar o enfermeiro em sua trajetória, uma vez que a enfermagem permanece em evolução e somos todos atores nesta arte.

Palavras chave: Enfermagem; História da Enfermagem; Cuidados de Enfermagem.

\section{INTRODUÇÃO}

Cuidar é uma atitude de ocupação, preocupação, responsabilização e afeto com o outro (Boff, 1999). Cuidar envolve um olhar integral ao ser humano, desde suas necessidades até o contexto cultural ao qual se insere, considerando que cada um possui seus valores, crenças, saberes e práticas de cuidados. Logo, cuidar é valorizar o ser humano na sua totalidade, é um cuidado feito com compaixão, interesse e com carinho, no qual o ser humano é olhado, escutado e sentido (Waldow, 2004).

Historicamente o cuidado era realizado por pessoas, na maioria das vezes mulheres, que ajudavam outras e atendiam suas necessidades. Os cuidados eram voltados para as crianças, as gestantes, o fogo, a caça, as plantas e as colheitas (Collière, 1989). Assim, cuidar passou a ser entendido como ajudar a viver e as mulheres desempenhavam papel fundamental no cuidado ao outro, sendo vistas como alguém que cuida.

Com o passar dos anos a mão de obra especializada foi requisitada para executar as ações de cuidado, e assim as mulheres que cuidavam passaram a serem reconhecidas como enfermeiras (Collière, 1989). Foi então com as ações de Florence Nightingale que a 
enfermagem passou a sistematizar o cuidado. Florence valorizava a arte por meio das ações de enfermagem, enfatizando conceitos de cuidado à saúde. Além destes aspectos, ressaltava a importância do cuidado amoroso e honesto, de forma que as enfermeiras, além do conhecimento científico, necessitavam de um elevado padrão moral e de criatividade (Stamm, 2002).

Entretanto, a necessidade de mão de obra especializada e o crescimento de profissionais na área da saúde influenciaram para que o cuidado fosse realizado de forma isolada e nas dimensões do corpo que necessitavam de tratamento, dando força ao modelo biomédico de cuidado, o qual estimula os profissionais da saúde a aderirem ao comportamento cartesiano (Barros, 2002).

Stamm (2002), ao tratar sobre a evolução do cuidado de enfermagem, cita alguns autores que foram determinantes nesse processo, como Boff, Leininger, Waldow e Watson. Para ela, os trabalhos desses autores chamaram atenção dos demais enfermeiros e trabalhadores da saúde para a dominação que estavam sofrendo pelo modelo biomédico, fazendo com que refletissem acerca da sua atuação e de novas concepções de cuidado na enfermagem.

Desta maneira, o cuidado de enfermagem passa a ser percebido como uma atitude essencial à vida. Que envolve amor, solidariedade, expressando um "saber-fazer" embasado na ciência e na ética, direcionado às necessidades do indivíduo, da família e da comunidade (Vale, Pagliuca, 2011).

A partir desta contextualização, entende-se que conhecer a história dos cuidados de enfermagem torna-se fundamental para integrar e contextualizar o enfermeiro na sua história e na arte de fazer a enfermagem. Corrobora estudo ao destacar que a valorização da evolução histórica da enfermagem permite conhecer como esta profissão foi se desenvolvendo ao longo dos anos e seu caminho para formar uma disciplina (Siles, 2010). Para tanto objetiva-se identificar as publicações disponíveis na literatura acerca da história da enfermagem, no campo dos cuidados realizados por enfermeiros.

\section{MÉTODO}

O presente estudo apresenta como método um dos recursos da prática baseada em evidências, a revisão integrativa da literatura, que vem permitir investigar o tema em questão. Fundamentou-se este estudo em publicações que detalham e validam esse método de pesquisa (Ursi, 2005; Ursi, Galvão, 2006; Mendes, Silveira, Galvão, 2008).

A revisão integrativa é um modelo que tem por finalidade reunir e sintetizar resultados de pesquisas sobre um determinado tema, possibilitando apontar lacunas no conhecimento e a síntese de múltiplos estudos publicados, permitindo conclusões gerais a respeito de um tema particular, ou uma aérea de estudo (Mendes, Silveira, Galvão, 2008).

Para a elaboração da presente revisão integrativa percorreu-se as etapas propostas por Mendes, Silveira e Galvão (2008), a saber: estabelecimento da questão de pesquisa; estabelecimento de critérios de inclusão e exclusão de artigos; categorização dos estudos; avaliação dos estudos; interpretação dos resultados; e a síntese do conhecimento. Desta maneira, para guiar a pesquisa, formulou-se a seguinte questão: como a história dos cuidados de enfermagem vem sendo discutida nas produções científicas?

A seleção dos artigos foi realizada por meio de uma busca na Biblioteca Virtual da Saúde (BVS). Assim, procurou-se ampliar as possibilidades da pesquisa. Os critérios de inclusão foram artigos que apresentassem nos títulos ou 
resumos referências à história da enfermagem ou aos cuidados de enfermagem; nos idiomas inglês, espanhol ou português. Os critérios de exclusão foram artigos que não se relacionassem a temática estudada e/ou não respondessem à pergunta de pesquisa.

Para iniciar a busca localizou-se o descritor "história da enfermagem"; após filtrou-se no campo assunto principal "cuidados de enfermagem"; na opção por limites definiu-se "humano"; no campo idioma selecionaram-se "inglês", "espanhol" e "português"; e no tipo de documento "artigo". Ressalta-se que não se estipulou o marco inicial por ano a fim de possibilitar maior abrangência na busca.

A busca foi realizada em agosto de 2014, e a partir desta encontrou-se um total de 69 publicações. Para realizar a captação dos conhecimentos produzidos nas publicações utilizou-se um quadro sinóptico proposto por Ursi e Galvão (2006), adaptado para este estudo, que contempla os seguintes aspectos: referência da pesquisa; intervenção estudada (objetivo); resultados e recomendações e/ou conclusões. A apresentação dos resultados e discussão dos dados obtidos será feita de forma descritiva, para possibilitar ao leitor que verifique a possibilidade de aplicar os resultados encontrados.

\section{RESULTADOS}

Os 69 estudos encontrados referem-se aos cuidados de enfermagem; destes 26 estavam indexados em Medical Literature Analysis and Retrieval System Online (MEDLINE), 25 no Índice Bibliográfico Espanhol de Ciências da Saúde (IBECS) e 18 na Literatura Latino-Americana e do Caribe em Ciências da Saúde (LILACS); 28 estavam na língua inglesa, 24 em espanhol e 18 em português. Após a seleção das produções e sua organização, realizou-se a leitura dos títulos e resumos a fim de enqua- drá-los na temática quanto à intervenção estudada. Sendo assim, após a leitura e exclusão dos artigos que não se enquadravam na temática de pesquisa e não respondiam à pergunta norteadora, foram selecionados 24 artigos.

Após esta etapa, realizou-se nova leitura destes artigos para delimitação dos resultados encontrados, dos quais foram excluídos mais nove, que tratavam da história da enfermagem em outros focos de estudo, que não os cuidados de enfermagem. A partir destas considerações, apresenta-se a seguir uma tabela demonstrativa dos 15 artigos selecionados (Tabela 1).

\section{DISCUSSÃO}

Os dados apresentados demonstram que a temática do cuidado na história da enfermagem vem sendo trabalhada em diferentes óticas, sendo as preponderantes relacionadas a influência de Florence Nightingale às ações de enfermagem e o surgimento da enfermagem em diversas sociedades e culturas. Destaca-se um significativo número de artigos publicados no ano de 2013 e a prevalência de publicações na Revista Cultura de los cuidados, da Espanha, com seis artigos. No Brasil, a revista com maior número de publicações foi a Escola Anna Nery Revista de Enfermagem com três artigos.

Para melhor visualização dos dados optou-se por realizar uma aproximação das temáticas trabalhadas nos artigos e apresentá-los em três categorias analíticas distintas, sobre a história dos cuidados de enfermagem em uma perspectiva geral; a história na Espanha; e a história no Brasil.

\section{História dos cuidados de enfermagem: uma perspectiva geral}

Santiago (2009) apresenta em seu texto a enfermagem como um exercício de práticas de cuidado, as quais são necessárias para a conser- 
vação da vida. Trata que no começo de tudo, os cuidados eram realizados por ações intuitivas, e que, na maioria das vezes, por mulheres que não tinham preparação ou conhecimentos específicos. Das mulheres era a responsabilidade de cuidar da família, da reprodução e da gestão das condições domésticas.

Para essa mesma autora o cuidado é inato na mulher e na mãe que, amorosamente, cuida de seu filho. Na enfermagem essa ideia prevalece, uma vez que as enfermeiras inseridas em diferentes contextos atuam de acordo com as orientações religiosas, sob a organização social e os valores de cada época. Para ser enfermeira era necessário possuir motivação religiosa, com doses de sacrifício, obediência, humildade e desprendimento dos bens materiais.

Segundo Santiago (2009), os enfermeiros são imprescindíveis na estrutura social, uma vez que contribuem na proteção, prevenção e melhorias da saúde e qualidades da saúde. Para Siles (2010), a profissionalização da enfermeira como protetora e cuidadora amorosa vem das concepções sociais de que a mulher tem deveres maternos e religiosos, sendo as responsáveis pelos cuidados com a família.

Coelho e Fonseca (2005) resgatam a construção histórica do cuidado, o qual existe desde que há vida humana. No transcorrer dos tempos, o cuidado se organizou do nascimento à morte, havendo uma intrínseca relação entre mulheres e cuidado. Para estes autores as mulheres podem ter adquirido um comportamento devido à maternidade, na qual elas cuidam do recém-nascido e do seu desenvolvimento, de outras mulheres na puberdade, gestação e parto, de adultos, idosos e moribundos, estando, assim, presentes em todo o ciclo vital dos seres humanos.

Neste interim, estudo de Siles e Solano (2011) destaca que os sentimentos relaciona- dos à maternidade fundamentavam as bases dos cuidados e motivava a função dos cuidadores nesta história da criação da enfermagem profissional. Para eles o papel que a mulher desempenhava dentro da família e da sociedade conferiu grande influência na base histórica da enfermagem.

O estudo de Padilha e Mancia (2005) ao investigar os ensinamentos da enfermagem e a influência sofrida pelas irmãs de caridade destaca que esta influência ainda existe de forma direta nos ensinamentos de amor e fraternidade, nos ditos acerca da valorização do ambiente e da divisão social do trabalho. Em vista disso, eles consideram enganoso atribuir somente às ideias de Florence o movimento para criação e desenvolvimento da enfermagem, uma vez que houve a influência religiosa nesse processo.

Nesta perspectiva, o estudo de Alves, Moreira e Junior (2005) trata da solidariedade franciscana como fundamento para a Enfermagem, em que o cuidado prestado por São Francisco é alicerçado na essência do ser humano, com ideia de solidariedade. A enfermagem é uma profissão de ajuda ao ser humano em suas necessidades biológicas, psicológicas e sociais, que partilha das ideias de São Francisco, o que perdura até os dias atuais. Segundo o estudo, o legado de Francisco de Assis para a Enfermagem é um exemplo de atenção ao ser humano, que transcende a assistência ao corpo debilitado, ampliando para a tríade corpo-mente-espírito.

Concernente a esta perspectiva, quando o profissional médico percebeu que o hospital compunha um campo de saber e consequente poder, ele passou a assumir este espaço e, passivamente, as irmãs de caridade o cederam. Entretanto, Florence com seus conhecimentos e a crença de que a enfermagem poderia 
ser uma profissão reconhecida e exercida por mulheres, propõe a retomada desse espaço. Assim, esta configuração de espaços no ambiente hospitalar consolidou os fundamentos que serviram de base para a atual prática de enfermagem, ainda priorizando os ideais de fraternidade e altruísmo (Padilha, Mancia, 2005).

Os feitos e escritos de Florence influenciaram diversas áreas além da enfermagem, como a estatística, administração em saúde, saúde pública, fisioterapia e espiritualidade. Ressalta-se que seus escritos são passíveis de adaptação nos mais variados cenários de cuidado, influenciando na experiência de ser enfermeira (Frello, Carraro, 2013). Da mesma forma, estudo que discute a identidade da enfermagem destaca que Florence teve grande importância na história desta profissão, e que seus ditos e ações contribuíram para a obtenção do reconhecimento da enfermagem pela sociedade (Siles, 2005).

Porto, Neto e Magalhães (2013) discorrem sobre a vivência do cuidado através dos tempos, representada pela imagem de Pietá (obra de Michelangelo que se traduz como símbolo para a enfermagem por sua imagem de ajuda, solicitude e humanidade). Para tanto, os autores adotaram a representação de cuidado de Ricouer, que prezava o respeito, a estima, a solicitude e o reconhecimento do valor humano como condições de realização da humanidade. Os autores entendem que a escultura de Pietá, pode representar um signo do cuidado, no processo de construção da imagem da Enfermeira.

Zuñiga, Morales e Gonzáles (2013), em seu trabalho retomam a história da enfermagem através dos tempos, quando eram responsáveis pela institucionalização do cuidado, com rotinas, horários, organização do espaço e tempo.
Segundo os mesmos autores, o processo histórico do cuidado vem caracterizando a identidade da enfermagem, que tem por objetivo manter o bem estar e a sobrevivência daqueles que necessitam.

A origem do trabalho do enfermeiro provém de complexas situações individuais e inerentes a cada ser humano. Por esta razão, torna-se importante considerar e conhecer o ser humano em sua completude, uma vez que este não está mais atrelado ao biológico, permeando a necessidade de aprofundar-se na gênese do ser humano para adequar seus cuidados ao contexto histórico (Arias, Riera,2013). Corroboram Zuñiga, Morales e Gonzáles (2013) ao destacarem a importância de o enfermeiro não esquecer que existe uma relação estreita com o sujeito de seu cuidado, uma vez que é preciso ter em vista que cada um está imerso em um contexto sociocultural e possui suas próprias práticas de cuidado.

Entende-se ser preciso resgatar os sentidos do cuidar, defendendo-se um cuidar pensado, sentido e exercido de forma contextualizada, que integra o singular, o particular e o estrutural, sedimentados na valorização das condições objetivas e subjetivas de quem é cuidado e de quem cuida (Coelho, Fonseca, 2005).

\section{História dos cuidados de enfermagem: tem- pos espanhóis}

Borredá et al (2012) abordam em seu trabalho uma reflexão sobre a história da enfermagem, suas raízes e valores atuais centrando-os na enfermagem moderna espanhola. Tratam da biografia de F. Nightingale e de F. Rubio e suas ações no campo da enfermagem. Destacam que há um paralelo entre Florence e Rubio, uma vez que seus estudos são similares no que tange às medidas sanitárias. O que pode ter influenciado a enfermagem na Espa- 
nha. Segundo Mestre et al (2013) a contribuição de enfermeiras com a saúde na Espanha iniciou nos anos 20 por meio de cuidado às famílias em seus domicílios, ensinando higiene, economia doméstica e cuidados de saúde infantil.

No texto de Garcia (2013) enfocam-se os manuais da Cruz Vermelha destinados a ensinar o cuidado de enfermagem para enfrentar a gripe no ano de 1918. Segundo este autor a Cruz Vermelha inspirou-se nos ditos de Florence Nightingale e foi fundamental para a saúde pública espanhola. Assim, os manuais avaliados compõem ensinamentos sobre a clínica, as técnicas de cuidado, puericultura, saúde materno-infantil, além de introduzir a história e organização da instituição. Nestes manuais, a enfermeira era encarregada dos cuidados aos feridos da guerra, subordinada às ordens médicas, além de realizar a higiene dos pacientes, a observação do ambiente e o controle de infecção.

Cadaya e Fernandes (2012) traçam uma evolução acerca da transição ocorrida, na Espanha, de atendente sanitário para enfermeiro diplomado. Essa evolução modificou a orientação dos cuidados integrais dispensados ao indivíduo, ampliou as funções do enfermeiro no âmbito assistencial, docente, gestor e investigador, o que proporcionou ampliar os conhecimentos científicos da própria disciplina. Há destaque no texto, no que se refere a evolução ocasionada por essa mudança, a forma de pensar do enfermeiro (holística), a forma de atuar (autonomia) e a forma de comunicação (plano de cuidados).

História dos cuidados de enfermagem: tempos brasileiros

Neto e Fugencio (2010) fazem um apanhado histórico da enfermagem no Brasil, em que destacam que no período de 1500 a 1822 o Brasil foi colônia de Portugal e, por isso, a enfermagem estava subjugada aos modelos portugueses. Nesse mesmo tempo, em 1741 a enfermagem era entendida como a aplicação de medicamentos ou tratamentos sob a prescrição de médicos.

Visualiza-se que até meados do século XIX, a enfermagem brasileira e a portuguesa caminhavam juntas, uma vez que eram influenciadas pela igreja, fundamentadas na imagem de vocação e caridade. As práticas de enfermagem, no início do século XX, no Brasil, eram desenvolvidas por pessoas leigas, irmãs de caridade e pessoas com treinamento ministrado por médicos ligados a diversas instituições hospitalares (Abrão et al, 2010).

Nascimento, Lima e Tyrrell (2003) abordam o desenvolvimento da enfermagem em Salvador, dando destaque para as unidades sanitárias. Segundo os autores o exercício da enfermagem teve início com as ações ligadas à saúde pública, com atuação dirigida ao controle e prevenção de problemas de saúde. Fazem uma ressalva que o atendimento a mulheres, por meio da consulta pré-natal, foi uma das primeiras atividades a serem desenvolvidas e se mantém até a atualidade na cidade de Salvador.

Abrão et al (2010), em seu estudo, analisam a influência da cultura germânica nos primórdios da enfermagem, na cidade de Recife em 1924, onde identificaram que a atuação das enfermeiras se dava pela dedicação e abnegação aos enfermos. Segundo as autoras um dos eventos que influenciou o campo da saúde daquela época foi a criação de um Hospital Modelo e a vinda de enfermeiras alemãs para Pernambuco.

Com estes acontecimentos se iniciou a organização das atividades de Enfermagem na 
cidade do Recife, as quais possuíam conhecimento sobre tecnologia, ciência e serviços médicos. Provavelmente, as enfermeiras alemãs que exerceram a enfermagem puderam contribuir para a ciência, a partir das práticas e condutas utilizadas, deixando a área hospitalar com uma enfermagem mais bem preparada (Abrão et al, 2010).

\section{CONSIDERAÇÕES FINAIS}

Revisitar a história dos cuidados de enfermagem permitiu identificar que são muitos os olhares lançados sobre essa temática. $\mathrm{Na}$ ocasião desta revisão de literatura os achados permitem refletir acerca da evolução dos cuidados, iniciados pelas irmãs de caridade e a visão além do seu tempo de Florence Nightingale. Pode-se conceber a participação de alemães, portugueses e religiosos no traçado da história da enfermagem, com destaque especial para as sociedades espanholas e brasileiras.
Nas produções analisadas, imprime-se o entendimento de que a enfermagem está em constante evolução, permeada por uma diversidade de profissionais de variadas culturas e conhecimentos. Em vista desse aspecto, é importante considerar a historicidade de nossa profissão e buscar conhecer as fontes de inspiração para que a enfermagem continue a exercer sua arte com excelência.

Destaca-se que a enfermagem apresenta um papel fundamental no cuidado ao ser humano, uma vez que ela permeia a compreensão dos contextos sociais aos quais os indivíduos se relacionam, sendo cada um único em sua forma. Entender a singularidade do ser cuidado e trabalhar para que a arte de fazer e ser enfermeiro perdure em nossas ações é fundamental para que a enfermagem continue evoluindo e seja cada vez mais reconhecida como ciência e disciplina do saber.

Tabela 1. Identificação das publicações selecionadas

\begin{tabular}{|c|c|c|}
\hline Identificação do artigo & Objetivos & Resultados \\
\hline $\begin{array}{l}\text { Nascimento E.R., Lima L.L.G., Tyrrell } \\
\text { M.A.R. O desenvolvimento da enfer- } \\
\text { magem e a inserção social das mu- } \\
\text { lheres. Rev. baiana enferm;18(1/2): } \\
\text { 11-18, jan.-ago. } 2003 \text {. }\end{array}$ & $\begin{array}{l}\text { Abordar aspectos do desenvolvi- } \\
\text { mento da enfermagem em unidades } \\
\text { sanitárias da Rede Básica Salvador e } \\
\text { sua contribuição para a crescente in- } \\
\text { serção social das mulheres. }\end{array}$ & $\begin{array}{l}\text { O exercício da enfermagem teve } \\
\text { início com as ações ligadas à saúde } \\
\text { pública, com atuação dirigida ao } \\
\text { controle e prevenção de problemas } \\
\text { de saúde. }\end{array}$ \\
\hline $\begin{array}{l}\text { Coelho E.A.C., Fonseca, R.M.G.S. } \\
\text { Pensando o cuidado na relação } \\
\text { dialética entre sujeitos sociais. Rev } \\
\text { Bras Enferm;58(2): 214-217, mar.- } \\
\text {-abr. } 2005 \text {. }\end{array}$ & $\begin{array}{l}\text { Busca oferecer subsídios teóricos } \\
\text { para a compreensão do cuidado em } \\
\text { saúde, valorizando-se a interação } \\
\text { entre as dimensões constitutivas de } \\
\text { sujeitos coletivos. }\end{array}$ & $\begin{array}{l}\text { Faz-se o resgate da construção his- } \\
\text { tórica do cuidado. Enfatiza-se a } \\
\text { contribuição de estudos da atuali- } \\
\text { dade na redefinição do cuidar com } \\
\text { ênfase na indissociabilidade entre } \\
\text { as dimensões expressivas e instru- } \\
\text { mentais. }\end{array}$ \\
\hline $\begin{array}{l}\text { Alves A.P.C., Moreira F.A.S., Silva } \\
\text { Júnior O.C. Cuidado e solidarie- }\end{array}$ & $\begin{array}{l}\text { Identificar as concepções de soli- } \\
\text { dariedade desenvolvidas por São }\end{array}$ & $\begin{array}{l}\text { O cuidado prestado por São Fran- } \\
\text { cisco, alicerçado na essência do ser }\end{array}$ \\
\hline
\end{tabular}




\begin{tabular}{|c|c|c|}
\hline $\begin{array}{l}\text { dade: São Francisco de Assis e a } \\
\text { enfermagem. Esc. Anna Nery Rev. } \\
\text { Enferm;9(2): 176-182, ago. } 2005 \text {. }\end{array}$ & $\begin{array}{l}\text { Francisco, correlacionar essas con- } \\
\text { cepções com o cuidado e analisar } \\
\text { a dimensão de sua obra como um } \\
\text { elemento inspirador para a enfer- } \\
\text { magem. }\end{array}$ & $\begin{array}{l}\text { humano, e sedimentado em todo } \\
\text { o movimento franciscano, confir- } \\
\text { ma a ideia da solidariedade como } \\
\text { fundamento para o cuidado e para } \\
\text { a Enfermagem. As contribuições do } \\
\text { personagem ultrapassaram as fron- } \\
\text { teiras da Idade Média e perduram } \\
\text { até os dias atuais. }\end{array}$ \\
\hline $\begin{array}{l}\text { Padilha M.I.C.S., Mancia J.R. Flo- } \\
\text { rence Nightingale e as irmãs de } \\
\text { caridade: revisitando a história. Rev } \\
\text { Bras Enferm;58(6): 723-726, nov.- } \\
\text {-dez. } 2005 \text {. }\end{array}$ & $\begin{array}{l}\text { Refletir acerca dos elos entre a prá- } \\
\text { tica de enfermagem e a influência } \\
\text { recebida das associações religiosas. }\end{array}$ & $\begin{array}{l}\text { A enfermagem profissional erigida } \\
\text { por Florence Nightingale sofreu in- } \\
\text { fluência direta dos ensinamentos de } \\
\text { amor e fraternidade. }\end{array}$ \\
\hline $\begin{array}{l}\text { Santiago M.A.M.. Pasado, presente } \\
\text { y futuro de la Enfermería: una apti- } \\
\text { tud constante. Rev. adm. sanit. siglo } \\
\text { xxi; } 7(2) \text { : } 243-260 \text {, abr.-jun. } 2009\end{array}$ & $\begin{array}{l}\text { Refletir sobre a importância de co- } \\
\text { nhecer a evolução histórica dos cui- } \\
\text { dados de cada cultura. }\end{array}$ & $\begin{array}{l}\text { Destaca-se que uma atitude cons- } \\
\text { tante ao longo dos tempos tem sido } \\
\text { o encontro com o outro. O outro } \\
\text { que é sujeito dos cuidados de enfer- } \\
\text { magem e a razão de suas ações. }\end{array}$ \\
\hline $\begin{array}{l}\text { Cristo Neto D.V., Fulgêncio I. Pos- } \\
\text { tilla Religiosa e a arte de enfermei- } \\
\text { ros: a primeira obra em português } \\
\text { para o ensino de enfermagem no } \\
\text { século XVIII. REME rev. min. } \\
\text { enferm;14(1): 119-122, jan.-mar. } \\
2010 \text {. }\end{array}$ & $\begin{array}{l}\text { Resgata-se a primeira obra escrita } \\
\text { em português com ensinamentos } \\
\text { para a realização dos cuidados de } \\
\text { enfermagem - a Postilla Religiosa e } \\
\text { a Arte de Enfermeiros, escrita por } \\
\text { Padre Frei Diogo Santiago em } 1741 .\end{array}$ & $\begin{array}{l}\text { Os preceitos exibidos permanecem } \\
\text { presentes nos códigos de ética e dis- } \\
\text { ciplinas do ensino da enfermagem } \\
\text { mais moderno. Pontos estes que } \\
\text { comprovam tratar-se da enferma- } \\
\text { gem como arte do cuidado e ciência } \\
\text { mais antiga do que aparenta ser. }\end{array}$ \\
\hline $\begin{array}{l}\text { Abrão F.M.S., Oliveira R.C., Freitas } \\
\text { N.S., Costa N.F.C.G., Sales V.M.B. } \\
\text { Influência germânica nos primór- } \\
\text { dios da enfermagem profissional } \\
\text { na cidade do Recife, Pernambuco } \\
\text { (1924-1927). Esc. Anna Nery Rev. } \\
\text { Enferm;14(2): 275-283, abr.-jun. } \\
2010 \text {. }\end{array}$ & $\begin{array}{l}\text { Análise da influência germânica no } \\
\text { campo da saúde nos primórdios da } \\
\text { enfermagem profissional na cidade } \\
\text { do Recife, Pernambuco. }\end{array}$ & $\begin{array}{l}\text { A influência se dá nos primórdios } \\
\text { da enfermagem profissional pelo } \\
\text { reconhecimento da atuação das } \\
\text { enfermeiras pela dedicação e abne- } \\
\text { gação aos enfermos no trabalho que } \\
\text { desenvolviam. }\end{array}$ \\
\hline $\begin{array}{l}\text { Cadaya N.M., Fernández M.L.F. } \\
\text { El rol enfermero. Cambios más sig- } \\
\text { nificativos entre ayudante técnico }\end{array}$ & $\begin{array}{l}\text { Identificar a evolução do papel do } \\
\text { enfermeiro, na Espanha, durante a } \\
\text { transição de ajudante técnico-sani- }\end{array}$ & $\begin{array}{l}\text { Apresenta a mudança do papel do } \\
\text { enfermeiro, que modificou sua } \\
\text { orientação com relação à admi- }\end{array}$ \\
\hline
\end{tabular}




\begin{tabular}{|c|c|c|}
\hline $\begin{array}{l}\text { sanitario y diplomado universitario } \\
\text { en Enfermería. Cult. cuid;16(33): } \\
\text { 22-29, mayo-ago. } 2012 \text {. }\end{array}$ & tário a diplomado em enfermagem. & $\begin{array}{l}\text { nistração dos cuidados integrais } \\
\text { do indivíduo, expandindo as suas } \\
\text { funções. }\end{array}$ \\
\hline $\begin{array}{l}\text { Santainés B.E., Faus G.F., Camaño } \\
\text { P.R., Sarturi F. ção Florence Ni- } \\
\text { ghtingale y Federico Rubio: refor- } \\
\text { madores de la Enfermería moderna } \\
\text { española. Cult. cuid; 16(33): 43-49, } \\
\text { mayo-ago. } 2012 \text {. }\end{array}$ & $\begin{array}{l}\text { Estabelecer um paralelo entre a } \\
\text { vida de Florence Nightingale e Fre- } \\
\text { derico Rubio; e identificar a reper- } \\
\text { cussão de Florence na enfermagem } \\
\text { moderna espanhola. }\end{array}$ & $\begin{array}{l}\text { Os dados obtidos apresentam si- } \\
\text { milaridades nos planos de estudo } \\
\text { e nas medidas sanitárias relacio- } \\
\text { nadas à saúde pública, que podem } \\
\text { significar que houve influência de } \\
\text { Florence sobre Rubio e suas ações } \\
\text { na Espanha. }\end{array}$ \\
\hline $\begin{array}{l}\text { Frello A.T., Carraro T.E. Contribui- } \\
\text { ções de Florence Nightingale: uma } \\
\text { revisão integrativa da literatura. } \\
\text { Esc. Anna Nery Rev. Enferm;17(3): } \\
\text { 573-579. } 2013\end{array}$ & $\begin{array}{l}\text { Identificar a contribuição dos feitos } \\
\text { e escritos de Florence Nightinga- } \\
\text { le nos artigos publicados entre os } \\
\text { anos de } 2004 \text { e } 2011 \text {, na percepção } \\
\text { de seus autores. }\end{array}$ & $\begin{array}{l}\text { Conclui-se que seus feitos e escritos } \\
\text { influenciaram diversas áreas além } \\
\text { da enfermagem, a exemplo da es- } \\
\text { tatística, administração em saúde, } \\
\text { saúde pública, fisioterapia e espiri- } \\
\text { tualidade. }\end{array}$ \\
\hline $\begin{array}{l}\text { Porto F., Neto M., Goulart M.S. } \\
\text { Pietá: a representação imagética do } \\
\text { cuidado. Cult. cuid;17(37): 13-21, } \\
\text { sept.-dic. } 2013 \text {. }\end{array}$ & $\begin{array}{l}\text { Reflexão sobre a vivência do cuida- } \\
\text { do através do tempo pelas noções } \\
\text { de cuidado e tempo do filósofo Paul } \\
\text { Ricoeur. }\end{array}$ & $\begin{array}{l}\text { A narrativa na linguagem imagé- } \\
\text { tica da escultura Pietá é uma das } \\
\text { possibilidades da representação da } \\
\text { experiência do cuidado. Funda- } \\
\text { mentou a compreensão histórica de } \\
\text { quem encomendou e a materializou } \\
\text { a obra que ao longo do tempo vem } \\
\text { representando para a Enfermagem } \\
\text { como um signo do cuidado. }\end{array}$ \\
\hline $\begin{array}{l}\text { Zúñiga B.J., Morales A.R.H., Gon- } \\
\text { zález A.B. La historia de enferme- } \\
\text { ría: trascendencia del fenómeno } \\
\text { cuidado y su relación con el tiempo. } \\
\text { Cult. cuid;17(36): 11-18, mayo-ago. } \\
2013 \text {. }\end{array}$ & $\begin{array}{l}\text { Analisar de forma hermenêutica a } \\
\text { relação entre cuidado e tempo e sua } \\
\text { importância histórico-filosófica. }\end{array}$ & $\begin{array}{l}\text { Identifica um paradoxo no trabalho } \\
\text { da enfermagem, onde estão seguin- } \\
\text { do horários, rotinas e atividades; o } \\
\text { que torna impossível a prestação } \\
\text { de cuidados com o tempo necessá- } \\
\text { rio para realizar o atendimento de } \\
\text { forma satisfatória, com qualidade e } \\
\text { incentivar o processo de construção } \\
\text { da enfermagem. }\end{array}$ \\
\hline $\begin{array}{l}\text { Arias J.M., Riera J.R.M. } \\
\text { El ser humano y la génesis del tra- }\end{array}$ & $\begin{array}{l}\text { Descrever a origem do trabalho do } \\
\text { enfermeiro e sua relação com o ser }\end{array}$ & $\begin{array}{l}\text { Considera-se ser importante co- } \\
\text { nhecer a complexidade que abrange }\end{array}$ \\
\hline
\end{tabular}




\begin{tabular}{|c|c|c|}
\hline $\begin{array}{l}\text { bajo enfermero comunitario. Cult. } \\
\text { cuid;17(36): 59-65, may-ago. } 2013 .\end{array}$ & humano de acordo com sua cultura. & $\begin{array}{l}\text { o ser humano, que vai além do bio- } \\
\text { lógico. Destaca-se que o enfermeiro } \\
\text { necessita relacionar-se com os ou- } \\
\text { tros, a fim de gerar uma rede que } \\
\text { não habite só aspectos fisiológicos, } \\
\text { mas sim abarquem o contexto biop- } \\
\text { sicossocial. }\end{array}$ \\
\hline $\begin{array}{l}\text { Mestre J.B., García C.C., Sánchez } \\
\text { M.E.G., Paramio P.G., López E.M.T. } \\
\text { Género y profesión en la evolución } \\
\text { histórica de la Enfermería Comuni- } \\
\text { taria en España. Enferm. clín;23(6): } \\
\text { 284-289, dic. } 2013 \text {. }\end{array}$ & $\begin{array}{l}\text { Os antecedentes históricos da ques- } \\
\text { tão de gênero, na Espanha, na me- } \\
\text { dida em que se pode ajudar a enten- } \\
\text { der muitos problemas e deficiências } \\
\text { que a enfermagem comunitária se- } \\
\text { gue mostrando na atualidade. }\end{array}$ & $\begin{array}{l}\text { A contribuição de enfermeiras com } \\
\text { a saúde na Espanha iniciou nos } \\
\text { anos } 20 \text { por meio de cuidado às fa- } \\
\text { mílias em seus domicílios, ensinan- } \\
\text { do higiene, economia doméstica e } \\
\text { cuidados de saúde infantil. }\end{array}$ \\
\hline $\begin{array}{l}\text { Alberto G.G. Los manuales de for- } \\
\text { mación de la Cruz Roja durante la } \\
\text { epidemia de gripe de 1918-1919. } \\
\text { Cult. cuid;17(36): 19-28, mayo-ago. } \\
\text { 2013. }\end{array}$ & $\begin{array}{l}\text { Analisar os manuais de formação } \\
\text { da Cruz Vermelha para identificar } \\
\text { em que momento pode-se situar a } \\
\text { introdução de conteúdos relaciona- } \\
\text { dos à saúde pública. }\end{array}$ & $\begin{array}{l}\text { A Cruz Vermelha contribuiu sobre- } \\
\text { maneira para a enfermagem na saú- } \\
\text { de pública espanhola, devido a sua } \\
\text { atuação na guerra e na epidemia da } \\
\text { gripe. }\end{array}$ \\
\hline
\end{tabular}

\section{REFERÊNCIAS}

- Abrão, F.M.S. et al. (2010). Influência germânica nos primórdios da enfermagem profissional na cidade do Recife, Pernambuco (1924-1927). Escola Anna Nery Revista de Enfermagem, 2(14),275-283.

- Alberto, G.G. (2013). Los manuales de formación de la Cruz Roja durante la epidemia de gripe de 1918-1919. Cultura de los Cuidos, 17(36),19-28.

- Alves, A.P.C., Moreira, F.A.S., Silva Júnior, O.C. (2005). Cuidado e solidariedade: São Francisco de Assis e a enfermagem. Escola Anna Nery Revista Enfermagem, 9(2),176-182.

- Arias, J.M., Riera J.R.M. (2013). El ser humano y la génesis del trabajo enfermero comunitario. Cultura de los Cuidados, 17(36),59-65.

- Boff, L. (1999). Saber cuidar: ética do humano, compaixão pela terra. Brasil, Editora Vozes.

- Barros, J.A.C. (2002). Pensando o processo saúde doença: a que responde o Modelo biomédico? Revista Saúde e Sociedade, 11(1),67-84.
- Cadaya, N.M., Fernández, M.L.F. (2012). El rol enfermero. Cambios más significativos entre ayudante técnico sanitario y diplomado universitario en Enfermería. Cultura de los Cuidados, 16(33),22-29.

- Coelho, E.A.C., Fonseca, R.M.G.S. (2005). Pensando o cuidado na relação dialética entre sujeitos sociais. Revista Brasileira de Enfermagem, 58(2),214-217.

- Collière, M.F. (1989). Promover a vida: da prática da mulher de virtude aos cuidados de enfermagem. Coimbra, Editora Ledil.

- Cristo Neto, D.V., Fulgêncio, I. (2010). Postilla Religiosa e a arte de enfermeiros: a primeira obra em português para o ensino de enfermagem no século XVIII. REME Revista Mineira de Enfermagem, 14(1),119-122.

- Frello, A.T., Carraro, T.E. (2013). Contribuições de Florence Nightingale: uma revisão integrativa da literatura. Escola Anna Nery Revista de Enfermagem, 17(3),573-579.

- Mendes, K.D.S., Silveira, R.C.C.P., Galvão, C.M. (2008). Revisão integrativa: método de pesquisa para incorporação de evidências na saúde e na enfermagem. Texto 
Contexto Enfermagem, 17(4),758-764.

- Mestre, J.B. et al. (2013). Género y profesión en la evolución histórica de la Enfermería Comunitaria en España. Enfermagem Clínica, 23(6),284-289.

- Nascimento, E.R., Lima, L.L.G., Tyrrell, M.A.R. (2003). O desenvolvimento da enfermagem e a inserção social das mulheres. Revista Baiana de Enfermagem, 18(1/2),11-18.

- Padilha, M.I.C.S., Mancia, J.R. (2005). Florence Nightingale e as irmãs de caridade: revisitando a história. Revista Brasileira de Enfermagem, 58(6),723-726.

- Porto, F., Neto, M., Goulart, M.S. (2013). Pietá: a representação imagética do cuidado. Cultura de los Cuidados, 17(37),13-21.

- Santainés, B.E. et al. (2012). Florence Nightingale y Federico Rubio: reformadores de la Enfermería moderna española. Cultura de los Cuidados, 16(33),43-49.

- Santiago, M.A.M. (2009). Pasado, presente y futuro de la Enfermería: una aptitud constante. Revista de Administración Sanitária Siglo XXI, 7(2),243-260.

- Stamm, M. (2002). Evolução do cuidado na enfermagem até o cuidado transdimensional: uma revisão de literatura. Ciência Cuidado e Saúde, 2(1),293-298.

Siles, J. G. (2005). La eterna guerra de la identidad enfermera: un enfoque dialéctico y deconstruccionista. Index de Enfermería, 50. Recuperado de http://www.index-f.com/indexenfermeria/50revista/5196.php

- Siles, J. G. (2010). Los cuidados de enfermería en el marco de la historia social y la historia cultural. Em C. González y F. Martínez (Eds.) La transformación de la enfermería. Nuevas miradas para la historia (pp.219250). Granada: Comares.

- Siles, J. y Solano M.C.. (2011). A história cultural e a estética dos cuidados de enfermagem. Rev. Latino-Am. Enfermagem. 19(5),1-10.

- Ursi E.S., Galvão C.M. (2008). Prevenção de pele no perioperatório: revisão integrativa da literatura. Revista Latino Americana de Enfermagem, 14(1),124-131.

- Ursi E.S. (2005). Prevenção de pele no perioperatório: revisão integrativa da literatura. (Dissertação). Universidade de São Paulo, São Paulo.

- Vale, E.V., Pagliuca, L.M. (2011). Construção de um con- ceito de cuidado de enfermagem: contribuição para o ensino de graduação. Revista Brasileira de Enfermagem, 64(1),106-113.

- Waldow, V.R. (2004). Os fundamentos filosóficos do cuidar. In V.R. Waldow (Ed.) O cuidado na saúde. Brasil: Editora Vozes.

- Zúñiga, B.J., Morales, A.R.H. y González, A.B. (2013). La historia de enfermería: trascendencia del fenómeno cuidado y su relación con el tiempo. Cultura de los Cuidados, 17(36),11-18. 